\title{
Exploring the Socio-Cultural Barriers to Modern Contraceptive Use among Pakistani Women
}

\author{
Aqeela Tabassum ${ }^{1}$, Altaf Ezid khan ${ }^{2}$, Muhammad Arif $^{3}$ and Malik Wajahat $\mathrm{Ali}^{4}$ \\ ${ }^{l}$ District Demographer, Population Welfare Department-Punjab \\ ${ }^{2}$ Secretary, Population Welfare Department-Punjab \\ ${ }^{3}$ Senior Head Master Govt. High School, Chakwal \\ ${ }^{4}$ District Population Welfare Officer, Population Welfare Department-Punjab
}

\begin{abstract}
Pakistan is the 6th most populous country of the world, while contraceptive prevalence rate is only $30 \%$. It is considerably low as compare to other Muslim countries. Iran has $74 \%$ CPR, Turkey $71 \%$, Morocco 63\%, Indonesia 61\%, Egypt 60\% Bangladesh 56\% and Malaysia 55\%. Though, Pakistan was one of the first Asian countries to begin family planning program but due to some socio-cultural barriers Pakistan could not achieved the desired results. The aim of the present study was to explore the socio-cultural barriers to use to modern contraceptive methods. The sample size of the present study was comprised of 600 married women. Stratified and systematic sampling technique was used for data collection. Data shows that $11.2 \%$ of the respondents did not know any modern method.It is found that $16.7 \%$ respondents were currently using the contraceptive methods, $23.7 \%$ dropped the methods and $59.6 \%$ respondents never used any contraceptive methods. The bi-variate analysis shows that age $(p=0.019)$, education $(p=0.000)$, income $(p=0.008)$, number of children $(p=0.000)$, spousal communication $(p=0.000)$, and response of in laws $(p=0.000)$ were significantly associated with the use of contraceptive methods whereas family structure $(p=0.171)$ and opinion about condom's use $(p=.080)$ are not significantly associated with the use of contraceptive methods. It is suggested that over inflated social and cultural taboos related to the concept and practices of family planning program should be excluded as part of social responsibility towards a national cause.
\end{abstract}

Key words: Contraceptive prevalence rate, Family Planning, socio-cultural barriers, modern contraceptive methods

\section{Introduction}

Family Planning is a reproductive policy that couples adopt to meet their reproductive goals. This includes the decision making about the timing of the first and upcoming births, limiting family size and using suitable and safe contraceptive methods (UN, 2002). There is great evidence that family planning improves health, reduces poverty, and empowers women (Bongaarts et al. 2012). Deliberately high-quality family planning programs boost fertility declines, thus improving health and advancing economies. According to the (World Bank, 2007) contraception is a best buy for development. By helping individuals to choose when to have children, family planning saves lives, it prevents unintended pregnancies, averts maternal and child deaths and prevents abortions. Unplanned pregnancies occur when effective contraception is largely inaccessible, or contraceptive method is not used correctly or consistently. It has been estimated that almost $40 \%$ unplanned pregnancies occur globally each year as a result of ineffective contraceptive use or failure of method or non-use of contraception (World Bank, 2007). More than 222 million women in developing countrieswho want to plan their families or protect themselves from unplanned pregnancy still facing unmet need for contraception and do not have access to basic family planning services (UNFPA, 2012). For many women and couples around the world, religious, cultural, gender, and social norms prevent the use of family planning (Anonymous, 2011). The researchers were particularly interested to identify the socio cultural barriers to use the modern family planning practices.In Pakistan, several obstacles identified to the use of modern contraceptives including; husbands' opposition, fear of side effects, health concerns, and dissatisfaction with sexual sensation when using them (Najafi, 2011). In particular, women were ten times more likely to have used a family planning service if her husband approved (Stephenson, 2004).

Three million pregnancies occur in Pakistan annually that are not planned (Gani, 2012). In Pakistan, high levels of unmet need (25\%) and low levels of contraceptive use (30\%) put women at risk for unintended pregnancies. In 2006-2007, 24\% of all births in Pakistan were unintended. Many women experiencing an unintended pregnancy resort to induced abortion (Population Council, 2013). Overall in Pakistan, 35 percent of married women are using contraceptive method, in which 26 percent of married women are using modern method and 9 percent using traditional methods. In Pakistani context, socio cultural values are promoting the population growth in the country. With the population of 180.4 million, Pakistan is the 6th most populous 
country of the world by its current growth rate of 2.1 percent per year. Pakistan has also experienced a slow decline in fertility and Total Fertility Rate (TFR) is 3.8 (NIPS, 2013). The population will double in the next 39 years compared to 79 years for SAARC region. Population is projected 229.6 million in 2025 and 314.3 million in 2050. This rapid population growth will be a hindrance to economic and social development (PRB, 2012). In contrast, significant proportion 42.3 percent women and 37.5 per cent men don't want more babies. So, there is dire need to define the actual problem existing in society whether there is problem of access or other perceived problems in the society that create hurdle in the adoption of modern methods. It is estimated 890,000 abortions are performed annually in Pakistan. The country has an abortion rate of 29 abortions per 1000 women of reproductive age. An estimated one pregnancy out of six ends in abortion. Pregnant women who wish to have an abortion are forced to visit illegal clinics run by midwives. Women generally do not use contraception because of inaccessibility, financial constraints, and objections by their husbands on religious grounds. Interestingly many men have objections to their wives using contraception but do not object to abortion (Casterline, et al., 2004).

Unplanned pregnancies are the major reason of high growth rate of population in Pakistan. The unmet need and high abortion rate also shows that the attitude of the people towards the small family, but some sociocultural factors createshindrances to promote practices of family planning. So, the researchers were particularly interested to explore the socio cultural values and motives which create hurdles to adopt the family planning practices. Though socio-economic advancement and cultural determinants seem to have effects on the perceptions, beliefs of common people and using of family planning methods but still the percentage of nonusers is quite higher in Pakistan as compared with other neighboring Muslim countries like Bangladesh and Iran. These countries launched family planning programs later than Pakistan but showed significant success. Different socio-cultural and psychosocial factors are responsible for the failure of contraceptive use in Pakistan and by identifying these factors a more effective policy can be made to decrease fertility rates and slow population growth in Pakistan.

\section{Methodology}

A cross-sectional survey was piloted with 600 currently married women to investigate the socioeconomic and cultural factors affecting their attitude towards modern family planning practices in district Chakwal. The researchers only interviewed those respondents who were currently married women aged 20-44, living with their husband, having at least one child, who never used modern method in the past, and who dropped contraceptive methods after used, current users of any traditional or modern methods. The researchers also designed the exclusion criteria for the selection of the respondents. The researcher did not entertain those respondents who were newly married, widows, divorcees and who were living separate from their husbands for last six months at the time of survey.

In the present study 600 married women of age 20-44 were selected through stratified random sampling technique from rural areas of district Chakwal. At the first stage 10 villages with equal proportion of households, were chosen randomly as sub sample from the 453 total villages of district chakwal. Secondly Systematic Random Sampling technique was used to select each Nth household. This is more operational sampling design, and it would represent the population quite better than simple random sampling method (Nachmias, 1992).A pre-planned and well organized questionnaire was prepared and used to collect the data. Face to face interviews were arranged to fill up the close-ended questions with married females. For data entry and data analysis SPSS version 16 was used. There were made contingency tables to correlate the different variables. Chi-square and Gamma tests were applied in testing the hypotheses and to make clear the weak or strong association between variables. In this study value of chi-square is calculated at $\alpha=0.05$.

\section{Results and Discussions}

This section deals with uni-variate and bivariate analysis regarding using to modern contraceptive methods insocio-cultural context. Marriage is an important social and religious obligation. Data shows that majority $60 \%$ of the respondents were married within their same cultural tribe and caste group (Endogamous marriages). An interesting finding was explored that most of the respondents were married within their sect (Firqa/Maslik). If they belong to Shiaamaslik then they have to marry to Shiaamaslik. Data shows that majority of the respondents $57 \%$ were living in nuclear families and $42 \%$ were living in joint family system. The family system is also an important indicator to use the family planning practices. Most of the women do not use family planning methods because they are not allowed from their mother-in-laws and other members of the families. Stephenson and Hennink, (2004) stated that a woman's use of family planning services was strongly linked to household socioeconomic status, approval of her husband and other family members.

Age at marriage is also much important determinant in the family planning matters and fertility. Women who got marry at their early ages; they are more exposed to long child-bearing period. According to Malthus theory of over-population, postponing marriage can be used as a source to control the rapid growing 
population. Researchers were interesting to find the early age at marriage cases, so collected data was divided into specific categories less than 18 years, median group and late age at marriage. Data above indicates an important finding that marriage at early age is happening mostly (30 percent) as compared to males (5 percent). The mean age at marriage for female was $20.9+3.4$ and mean age for male $26.2+5.1$ indicated that the female age at marriage is comparatively low as compare to male. Similar results found by Hakim et al. 1998 stated that $17 \%$ of teenagers are currently married in Pakistan. There is an apparent difference in the education level of the respondent and their husbands. The $77.7 \%$ respondents were illiterate as compare to $88.7 \%$ of their husbands. The mean education of the respondents $8.13 \pm 2.70$ and their husbands $8.74 \pm 2.51$ shows middle level of literacy rate in study area and education also have sound impact to use the modern contraceptive methods.

Having knowledge about different modern contraceptive methods is an important indicator of contraceptive prevalence rate in a society. Data shows that $11.2 \%$ of the respondent did not know any method, $46.0 \%$ knew about 1-3 methods and 42.8\% respondent knew more than 4 method's names. Majority of the respondents were non-users. But interestingly results explored that majority of the women are aware about family planning methods but still have never used contraceptive methods. So it can be interpreted that knowledge about methods is not the barrier. Status of currently use of contraceptive practices is also an important factor for measuring the contraceptive prevalence rate in a society. It is found that $16.7 \%$ respondents were currently using the contraceptive methods, $23.7 \%$ respondents dropped the methods and 59.6\% respondents never used any contraceptive methods. It shows that major proportion of currently married women had never used modern contraceptive methods. The present finding line up with NIPS,(2013) and PDHS (2013) pointed out that 64.6\% and $65 \%$ married couple did not use any contraceptive methods respectively and it instigate high unmet need $25 \%$. The respondents who were using modern contraceptive methods, $6.8 \%$ respondents stated that used oral pills, 58.1\% used condoms, 5.4\% used Injections, 10.8 were using IUD and 18.9\% respondents were sterilized. PDHS, (2013) also found that majority of the modern contraceptive user were using the condoms and sterilization. Bibiet al.,(2012) found that oral contraceptive pills were commonly used method in rural areas of Sindh Pakistan.

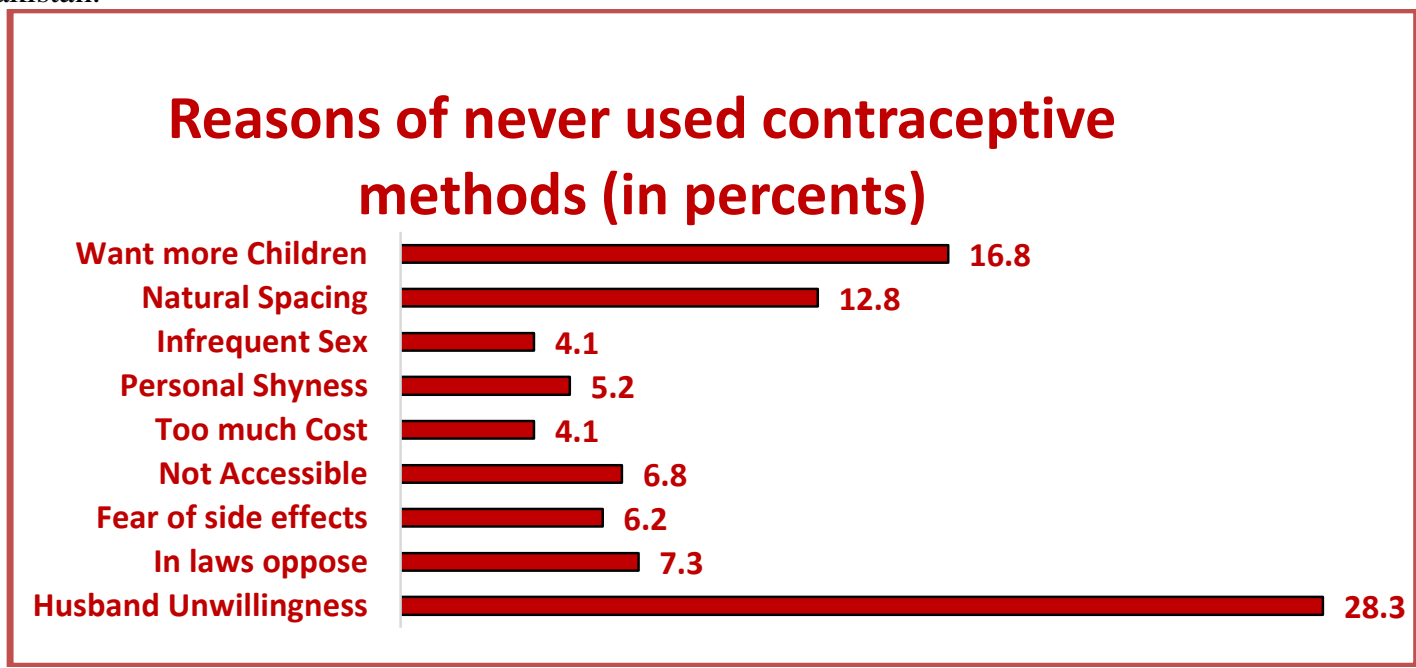

The contraceptive prevalence rate in Pakistan is very low. The researchers were particularly interested to explore the socio-cultural barriers to modern contraceptive use in the study area. Data shows that more than one fourth $28 \%$ respondents reported that their husbandswere not willing to use any contraceptive method and $7.3 \%$ respondents reported that they never used any family planning method because of their in-laws opposition. A small proportion of the respondents $5.2 \%$ stated that because of shyness due to the value of our family and $16.8 \%$ respondents were in the opinion that we want to produce more children. In male dominant society mostly females cannot play an instrumental role. Anonymous, (2011) highlighted the barriers to contraceptive use and concluded that husband's opposition, fear of side effects, no access to contraceptive services, religious unacceptability of contraceptive use is the main obstacles to contraceptive use in Pakistan.

Table 1: Distribution of the respondents according to their mobility freedom

\begin{tabular}{|c|c|c|c|c|c|c|c|c|c|c|}
\hline \multirow{2}{*}{$\begin{array}{l}\text { Sr. } \\
\text { No }\end{array}$} & \multirow[t]{2}{*}{ Statements } & \multicolumn{2}{|c|}{ Great extent } & \multicolumn{2}{|c|}{ Some extent } & \multicolumn{2}{|c|}{ Not certain } & \multicolumn{2}{|c|}{ Not at all } & \multirow{2}{*}{$\begin{array}{l}\text { Mean } \\
1.74\end{array}$} \\
\hline & & $\mathbf{F}$ & $\%$ & $\mathbf{F}$ & $\%$ & $\mathbf{F}$ & $\%$ & $\mathbf{F}$ & $\%$ & \\
\hline 1 & Go out alone & 240 & 40 & 256 & 42.7 & 95 & 15.8 & 9 & 1.5 & 2.77 \\
\hline 2 & To do job outside & 70 & 11.7 & 55 & 9.2 & 404 & 97.3 & 71 & 11.8 & 1.72 \\
\hline 3 & $\begin{array}{l}\text { Talking with other women } \\
\text { related to family planning }\end{array}$ & 287 & 47.8 & 188 & 31.3 & 117 & 19.5 & 8 & 1.3 & 1.70 \\
\hline 4 & $\begin{array}{l}\text { Going alone } \\
\text { Hospital/FWC }\end{array}$ & 305 & 50.8 & 190 & 31.7 & 99 & 16.5 & 6 & 1.0 & 1.63 \\
\hline
\end{tabular}


Above table shows the extent of mobility allowance of the respondents. Data shows that $40 \%$ and $42.7 \%$ respondents were great extent and to some extent agreed that they have allowance to go out alone from home. When asked to the respondents about their permission to do job out of the home, a large majority of the respondents $97.3 \%$ were not certain it denotes that their less decision making power. It is found that majority of the respondents discuss about the family planning practices. Data shows that $47.3 \%$ and $31.3 \%$ respondent's great extent and some extent discussed with other females about family planning practices respectively, 50.8\% respondents reported that they are independent to go alone to the hospital at great extent and $31.7 \%$ some extent agreed that to go alone to hospital. $34.8 \%$ respondents alleged that they informed their daughters about the reproductive health great extent, $17.2 \%$ some extent and $22.8 \%$ respondents were not discussed with their daughters about the reproductive health. SWRHFPS (2003), pointed out that one in three women was not allowed to leave her home alone and $42 \%$ of women who were able to go to heath centers on their own were using contraception compared to half that proportion. $21 \%$ who were not allowed to go to these facilities at all.

Table 2: Chi-Square and Gama values showing relationship between socio-economic and cultural factors and their status of contraceptive use.

\begin{tabular}{|c|c|c|c|c|c|c|}
\hline \multicolumn{2}{|l|}{ Variables } & $\begin{array}{l}\text { Chi-square } \\
\text { value }\end{array}$ & D.F. & Sig. & $\begin{array}{l}\text { Gamma } \\
\text { value }\end{array}$ & Sig. \\
\hline \multirow{7}{*}{$\begin{array}{l}\text { Background } \\
\text { Characteristics }\end{array}$} & Age & 70.346 & 48 & $.019^{*}$ & -.070 & $.110^{\mathrm{NS}}$ \\
\hline & Education & 38.052 & 12 & $.000 * * *$ & .172 & $.001 * *$ \\
\hline & Family Income & 20.672 & 8 & $.008 * *$ & .154 & $.013 *$ \\
\hline & Economic status & 24.673 & 4 & $.000^{*} * *$ & -.026 & $.690^{\mathrm{NS}}$ \\
\hline & Living children & 53.99 & 16 & $.000 * * *$ & -.245 & $.000 * *$ \\
\hline & Family structure & 3.528 & 2 & $.171^{\mathrm{NS}}$ & -.126 & $.089^{\mathrm{NS}}$ \\
\hline & Ideal Family Size & 29.169 & 10 & $.001^{* *}$ & -.104 & $.071^{\mathrm{NS}}$ \\
\hline \multirow{8}{*}{$\begin{array}{ll}\text { Knowledge } & \text { of } \\
\text { Modern Methods } & \end{array}$} & Methods remembered & 2.098 & 16 & $.000 * * *$ & -.192 & $.000 * *$ \\
\hline & Opinion about condom & 11.283 & 6 & $.080^{\mathrm{NS}}$ & -.038 & $.511^{\mathrm{NS}}$ \\
\hline & Opinion about O.P & 18.320 & 6 & $.005^{* *}$ & -.019 & $.731^{\mathrm{NS}}$ \\
\hline & Opinion about Injectable & 12.194 & 6 & $.058 *$ & -.002 & $.975^{\mathrm{NS}}$ \\
\hline & Opinion about IUD & 50.285 & 6 & $.000 * * *$ & -.149 & $.010^{*}$ \\
\hline & Opinion about Implant & 52.556 & 6 & $.000^{*} * *$ & -.063 & $.385^{\mathrm{NS}}$ \\
\hline & Opinion about Female sterilization & 37.123 & 6 & $.000 * * *$ & -.123 & $.051 *$ \\
\hline & Opinion about Vasectomy & 45.431 & 6 & $.000 * * *$ & -.095 & $.248^{\mathrm{NS}}$ \\
\hline \multirow{10}{*}{$\begin{array}{l}\text { Socio-cultural } \\
\text { Barriers }\end{array}$} & Freedom in FP matters & 8.613 & 2 & $.013^{*}$ & .031 & $.685^{\mathrm{NS}}$ \\
\hline & Spousal Communication & 69.478 & 4 & $.000 * * *$ & .156 & $.011 *$ \\
\hline & Permission to go out alone & 13.615 & 6 & $.034 *$ & .114 & $.056^{\mathrm{NS}}$ \\
\hline & Allowed to do job & 25.735 & 6 & $.000^{*} * *$ & .033 & $.655^{\mathrm{NS}}$ \\
\hline & $\begin{array}{l}\text { Permission to go to Hospital/FWC } \\
\text { alone }\end{array}$ & 29.05 & 6 & $.000 * * *$ & .110 & $.071^{\mathrm{NS}}$ \\
\hline & Husband dispproval & 62.546 & 4 & $.000 * * *$ & -.212 & $.006^{* *}$ \\
\hline & Husband wants more children & 17.029 & 4 & $.002 * *$ & .141 & $.025^{*}$ \\
\hline & Response of In-laws & 24.437 & 4 & $.000^{* * *}$ & -.049 & $.408^{\mathrm{NS}}$ \\
\hline & Mother in Law want more children & 15.496 & 4 & $.004 * *$ & .073 & $.256^{\mathrm{NS}}$ \\
\hline & Exposure to Media & 29.176 & 6 & $.000 * * *$ & -.022 & $.700^{\mathrm{NS}}$ \\
\hline
\end{tabular}

Dependent Variable: Status of Contraceptive Use

$(* * *=$ Highly Significant $), \quad(*=$ Significant $), \quad(\mathrm{NS}=\quad$ Non-Significant $)$

Using of modern contraceptive methods is vitally important in relation to human health and human rights and it is defined within the socio-economic and cultural context. Chi-square and Gamma tests are applied to know the association between the socio-economic, cultural variables and status of contraceptive use. The results show that education, economic status and number of living children, are highly significant at $1 \%$ level of significance having chi-square values 38.05, 24.67 and 53.99 indicate that all these variables are significantly associated with the use of modern contraceptive methods which is taken as dependent variable. Gamma values of education and income $(0.172$ and 0.154$)$ shows a positive relationship between the variables. It means if the respondents more educated and had better family income they had also more use of family planning methods. Majeed, (2012) Chisquare analysis showed that the use of contraceptive methods was significantly associated with age (p-value 0.000 ), parity (p-value 0.001$)$, knowledge (0.000) no. of years after marriage (p-value 0.000$)$ and frequency of intercourse (0.000).

Chi-square value (2.098) shows a highly significant $(\mathrm{P}=.000)$ association between ${ }^{\text {ee }}$ Number of modern contraceptive methods remembered by the respondents and their use of family planning methods. Awareness about modern contraceptive methods is highly significant at $5 \%$ level of significance having chi-square values $18.32,50.28,52.55,37.12$ and 45.43 indicate that opinion about all these variables respectively Oral pills, IUD, Implant, Female sterilization and vasectomy are significantly associated with the use of modern contraceptive 
methods. Interestingly opinion about condom and injectable has non-significant association with the use. The Gamma values also indicate that there is indirect relationship between these variables.

Bivariate analysis demonstrates a highly significant relationship between socio cultural barriers and use of modern contraceptive methods. The chi-square values of freedom of the woman in family planning matters which is 8.61 and permission to go out alone which is 13.61 are significant at $5 \%$ level of significant but the Gamma value shows non-significant relationship between variables. The chi-square values of the variable spousal communication (69.47), allowed to do job alone (25.73), permission to go to hospital alone (29.05), husband approval to FP (62.54), response of In-laws (24.43) and exposure to media (29.17) are very strongly significant at $1 \%$ level of significance except husband approval all other having slight relationship between the variables. Mother-in-law's wish for more children also plays an important role leading less use of family planning methods. And in this study this variable has significant results. Fikreeet al.,(2001) found that, in the traditional Pakistani patriarchal and patrilocal family structure, a woman's mother-in-law appears to have a strong influence on the couple's reproductive decision-making.

\section{Conclusion}

National findings demonstrated that women want average 3 children, but stubbornly, having 4 children. One out of four women has unmet need. This study covers the rural area and CPR for any modern method in rural areas of Pakistan is 23 percent. Due to the socio-cultural values i.e. low level of education, women mobility constraints, negative attitude of the husbands and in laws are the major factors of not using the modern contraceptive methods. The result shows that age, education, income, number of children, spousal communication and response of in laws are were significantly associated with the use of contraceptive methods. It is suggested that over inflated social and cultural taboos related to the concept and practices of family planning program should be excluded as part of social responsibility towards a national cause and the government should take this issue on priority with political commitment.

\section{Reference}

[1]. Anonymous. 2011. Socio-cultural barriers to family planning. http://www.theguardian.com/journalismcompetition/2011-themefamily-planning

[2]. Anonymous ${ }_{1}$. 2011. Physical, Social and Financial Problems of Females using Various Methods of Contraception. Gender watch

[3]. Bibi,S., H. Soomro, S. Ghaffar, M. A. Pir. 2012. Met and unmet need of family planning and associated factors in a remote rural area of Sindh, Pakistan. 28(3):400-403

[4]. Bongaarts, J., J. Cleland, J.W. Townsend, J.T. Bertrand, and M.D. Gupta. 2012. Family Planning Programs for the 21st Century. Rationale and Design. New York: The Population Council, Inc.

[5]. Casterline, J., S. Singh and Z. Sathar. 2004. Unwanted Pregnancy and Post-Abortion Complications in Pakistan: Findings from a National Study. Population Council, Islamabad

[6]. Fikree, F. F., A. Khan, M. M. Kadir, F. Sajan and M. H. Rahbar. 2001. What Influences Contraceptive Use among Young Women in Urban Squatter Settlements of Karachi, Pakistan. International Family Planning Perspectives. 27(3)

[7]. Gani, A. 2012. 3m unplanned pregnancies occur in Pakistan: The Nation. June 28, 2012

[8]. Majeed, T., U. Qadir, Z. Mahmood, Z. Azeem, Y. Azeem, Z. Aftab. 2012. Prevalence of Contraceptive Methods and Factors Influencing the Choice of Temporary Vs Permanent Methods of Contraception: A Multicentre Urban Study. Pakistan Journal of Medical and Health Sciences. 6, 2

[9]. Najafi, F.S. A., H. A. Rahman and M. H.Juni. 2011. Barriers to Modern Contraceptive Practices among Selected Married Women in a Public University in Malaysia. Global Journal of Health Science 3( 2)

[10]. NIPS, 2013. National Institute of Population Studies. Family Planning Pakistan Demographic and Health Survey 201213.Islamabad: NIPS. Measures DHS ICF International Calverton, Maryland, USA: Preliminary Report Page 15-16

[11]. PDHS. 2013. Pakistan Demographic and Health Survey. National Institute of Population Studies Islamabad, Pakistan

[12]. Population Council. 2013. Post abortion Care in Pakistan. Guttmacher Institute.

[13]. PRB, 2012. Population Reference Bureau World Population data sheet Population Reference Bureau

[14]. Stephenson, R., M. Hennink. 2004. Barriers to Family Planning Service Use among the Urban Poor in Pakistan. Opportunities and Choices Working Paper No. 2, 34 pp.

[15]. SWRHFPS, 2003.Status of Women, Reproductive Health and Family Planning Survey. National Institute of Population Studies, Islamabad, Pakistan

[16]. UN, 2002. World Population Monitoring Report. New York: United

[17]. UNFPA. 2012 .State of World Population.By Choice, Not by Chance; Family Planning Human Rights and Development.Pp 1. www.popcouncil.org

[18]. World Bank. 2007. Why contraception is a Best Buy. Disease Control Priorities Project Policy Brief. Washington DC: DCP2 